\title{
IMPLEMENTASI DAN ANALISIS ARDUINO DALAM RANCANG BANGUN ALAT PENYIRAM TANAMAN OTOMATIS MENGGUNAKAN APLIKASI ANDROID
}

\author{
${ }^{1}$ Yessi Mardiana, ${ }^{2}$ Riska \\ Rekayasa Sistem Komputer, Fakultas Ilmu Komputer Universitas Dehasen Bengkulu \\ Jl. Meranti Raya No. 32 Kota Bengkulu 38228 Telp. (0736) 22027, 26957 Fax. (0736) 341139 \\ ${ }^{1}$ yessimrdegmail.com \\ ${ }^{2}$ riska.iskandar@unived.ac.id
}

\begin{abstract}
Abstrak: Selama ini, penyiraman tanaman dilakukan secara manual. Akan tetapi, terkadang kita tidak punya cukup waktu untuk menyiram tanaman. Oleh karena itu, dibutuhkan suatu alat yang dapat membantu meringankan kegiatan menyiram tanaman. Alat tersebut berupa sistem yang dapat bekerja secara otomatis. Dengan menggunakan alat ini, maka diharapkan penyiraman tanaman dapat dilakukan pada waktu dan saat yang tepat. Dalam penelitian ini, alat penyiram tanaman otomatis dengan android berbasis Arduino Uno, menggunakan Arduino Uno sebagai sistem pengendalian, modem digunakan sebagai penerimaan perintah yang dikirim melalui smartphone android. Penelitian ini bertujuan untuk memberikan kemudahan dalam penyiraman tanaman secara otomatis berdasarkan waktu yang ditentukan dan kondisi cuaca yang terjadi dengan memnggunakan rain sensor sehingga proses penyiraman tanaman dapat dijadwalkan sesuai dengan kebutuhan dari tanaman tersebut.
\end{abstract}

Kata Kunci: Alat Penyiram Tanaman, Arduino, Android

Abstract: During this time, watering the plants is done manually. However, sometimes we don't have enough time to water the plants. Therefore, we need a tool that can help ease the activities of watering plants. The tool is a system that can work automatically. By using this tool, it is expected that watering the plants can be done at the right time and time. In this research, automatic plant watering devices with Android based on Arduino Uno, using Arduino Uno as a control system, modems are used as receiving commands sent via Android smartphones. This study aims to provide convenience in watering plants automatically based on the specified time and weather conditions that occur using a rain sensor so that the plant watering process can be scheduled according to the needs of the plant.

Keywords: Plant Watering Tools, Arduino, Android

\section{PENDAHULUAN}

Sejarah berkembangnya era globalisasi dan informasi, penggunaan komputer telah mencakup di segalah bidang. Penggunaan komputer terbukti banyak membantu kita dalam melakukan pekerjaan dengan baik, dapat kita lihat dalam kehidupan sehari-hari baik dari proses suatu pekerjaan, contohnya di perkantoran semua menggunakan komputerisasi untuk mempermudah proses dalam melakukan pekerjaan.

Dimana perkembangan teknologi ini juga meliputi dalam bidang pertanian. Seperti yang dapat kita lihat dalam kehidupan sehari-hari banyak sekarang ini produk-prodiveuk untuk pekerjaan dibidang pertanian yang sudah semi otomatis maupun yang otomatis, seperti halnya penyiraman tanaman.

Penyiraman tanaman merupakan suatu kegiatan yang perlu diperhatikan dalam melakukan pemeliharaan tanaman, dikarenakan tanaman memerlukan asupan air yang cukup, sebab Tingkat 
Jurnal Pseudocode, Volume VII Nomor 2, September 2020, ISSN 2355-5920, e-ISSN 2655-1845 www.ejournal.unib.ac.id/index.php/pseudocode

kesuburan dapat dipengaruhi dengan intensitas air yang dikandungnya[1]. Salah satu faktor penyebab kurangnya produktifitas pertanian di Indonesia adalah mayoritas petani di Indonesia masih menggantungkan pada perubahan iklim dalam pengolahan lahan pertanian[2].

Namun, pemilik tanaman atau petani biasanya melakukan penyiraman secara manual dengan memberikan air sesuai jadwal. Cara ini kurang efektif, karena membutuhkan banyak waktu dan tenaga. Pemilik juga tidak bisa meninggalkan tanaman dalam kurun waktu yang lama, karena tanaman dapat kekurangan air dan menyebabkan kematian[3][4]. Alat tersebut dapat dikontrol menggunkan aplikasi android yang dihubungkan baik melalui media bluetooth ataupun sinyal operator selular dan juga internet.

Oleh karena itu perlu dirancang sebuah alat yang dapat membantu petani untuk penyiraman tanaman secara otomatis berdasarkan waktu yang ditentukan dan kondisi cuaca yang terjadi sehingga proses penyiraman tanaman sudah dijadwalkan sesuai dengan kebutuhan dari tanaman tersebut. harapan dari perancangan alat ini agar dapat membantu manusia dalam melakukan pekerjaan penyiraman tanaman walaupun sedang tidak berada di rumah ataupun di lokasi pertanian.

\section{LANDASAN TEORI}

\subsection{Mikrokontroller}

Mikrokontroler merupakan perangkat semi konduktor yang terdiri dari mikroprosesor, input output, dan memori yang terdapat dalam satu kemasan chip sehingga mikrokontroler dapat berfungsi sebagai pengontrol dalam suatu sistem. Dunia mikroelektronika saat ini telah mengalami perkembangan yang sangat pesat. Perkembangan terakhir, yaitu generasi AVR (Alf and Vegard's
Risc processor), memiliki arsitektur RISC 8 bit, di mana semua instruksi dikemas dalam kode 16 bit (16 bits word) dan sebagian besar instruksi di eksekusi dalam 1 (satu) siklus clock, berbeda dengan instruksi MCS51 yang membutuhkan 12 siklus clock. Hal ini disebabkan arsitektur kedua jenis mikrokontroler ini berbeda. AVR berteknologi RISC (Reduced Instruction Set Computing), sedangkan seri MCS51 berteknologi CISC (Complex Instruction Set Computing)[5].

\subsection{Arduino}

Arduino adalah platform prototyping opensource hardware yang dapat digunakan untuk membuat projek berbasis pemrograman. Hardware Arduino memiliki prosesor mikrokontroler ATMega yang dirilis oleh Atmel AVR, tetapi software yang digunakan memiliki bahasa pemrograman tersendiri. Arduino dirancang untuk memudahkan pengguna elektronik atau siapapun yang ingin mengembangkan peralatan elektronik interaktif berdasarkan hardware dan software yang fleksibel dan mudah untuk digunakan. Sebagai contoh adalah jenis Arduino yang paling banyak digunakan, yaitu Arduino UNO. Jenis ini menggunakan mikrokontroler keluaran Atmel, yaitu seri ATmega328[6]. Arduino merupakan IC (Integrated Circuit) yang open source berbasis AVR dimana logika pemrograman diinput kedalamnya, selanjutnya diproses sehingga menghasilkan output berdasarkan logika / perintah inputnya. Pemrograman pada Arduino ini menggunakan compiler $\mathrm{C}$ dengan library untuk mempermudah user dalam pembuatan project [7]. 
Jurnal Pseudocode, Volume VII Nomor 2, September 2020, ISSN 2355-5920, e-ISSN 2655-1845 www.ejournal.unib.ac.id/index.php/pseudocode

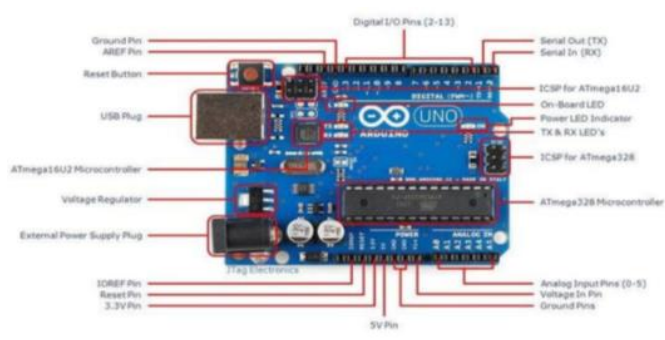

Gambar 1. Arduino Uno R3

Secara umum Arduino terdiri dari dua bagian, yaitu:

a. Hardware : papan input/output (I/O)

b. Software : Software Arduino meliputi IDEuntuk menulis program, driver untukkoneksi dengan komputer, contoh programdan library untuk pengembanganprogram.

c. Arduino UNO memiliki fitur-fitur baru sebagai berikut:

1) Pinout 1.0: ditambah pin SDA dan SCL yang dekat dengan pin AREF dan dua pin baru lainnya yang diletakkan dekat dengan pin RESET, IOREF .

2) Sirkuit RESET yang lebih kuat

3) ATmega 16U2 menggantikan 8U2

\subsection{Android}

Android merupakan sebuah sistem operasi yang berbasis linux untuk perangkat portable seperti smartphone dan komputer tablet. Android menyediakan platform terbuka (open source) bagi programmer untuk mengembangkan aplikasi sendiri pada berbagai perangkat dengan sistem android [8].

\subsection{Rain Sensor}

Rangkaian detektor hujan merupakan rangkaian sederhana yang dapat mendeteksi telah terjadi hujan disekitar alat tersebut yang dipasang pada genting rumah. Pada dasarnya rangkaian detektor hujan ini mendeteksi adanya hujan melalui terhubungnya terminal sensor oleh air hujan.Sensor air pada rangkaian detektor hujan inidapat dibuat dengan PCB kemudian didesain sedemikian rupa sehingga prinsip terjadihubungan antara 2 terminal pada saat terkena air terpenuhi. Sebagai indikator bila sensor tersebut mendeteksi adanya hujan maka rangkaian ini akan memberikan sinyal output berupa bunyi buzzer[9]

\subsection{Relay}

Relay adalah suatu peranti yang menggunakan electromagnet untuk mengoperasikan seperangkat kontak sakelar. Susunan paling sederhana terdiri dari kumparan kawat penghantar yang dililit pada inti besi. Bila kumparan ini di energikan, medan magnet yang terbentuk menarik armatur berporos yangdigunakan sebagai pengungkit mekanisme sakelar. setelah itu relay ini akan bekerja menghubungkan arus dari baterai ke motor. Disini digunakan Kipas angin, yang akan membuat suhu ruangan menjadi sejuk dan memberi pengaruh terhadap sensor DHT11 sehingga tegangan pada sensor akan menjadi turun dan kemudian relay akan otomatis mematikan seluruh sensor begitu pula sebaliknya ketika suhu ruangan meningkat kembali maka keseluruhan system diatas akan bekerja kembali[10].

\section{METODE PENELITIAN}

Dalam penyusunan penelitian ini, penulis menggunakan beberapa langkah atau metode, antara lain: 
Jurnal Pseudocode, Volume VII Nomor 2, September 2020, ISSN 2355-5920, e-ISSN 2655-1845 www.ejournal.unib.ac.id/index.php/pseudocode

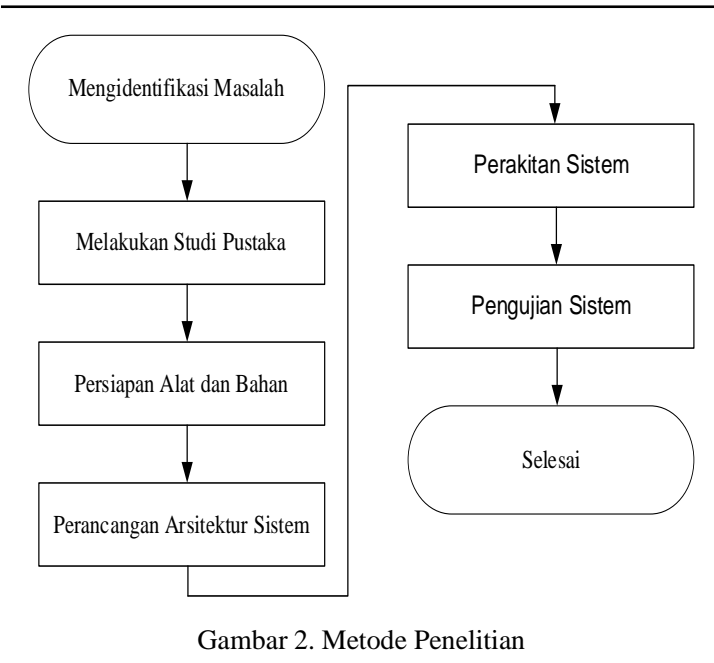

a. Mengidentifikasi Masalah

Dalam tahap perancangan sebuah sistem, identifikasi terhadap masalah yang ditemui merupakan sesuatu hal yang penting, sebab pada tahan inilah proses analisis terjadi dan mendapatkan sebuah gambaran dari solusi yang akan ditawarkan. Dalam penelitian ini identifikasi masalah yang penulis sudah dapatkan adalah Selama ini, penyiraman tanaman dilakukan secara manual. Akan tetapi, terkadang kita tidak punya cukup waktu untuk menyiram tanaman. Oleh karena itu, dibutuhkan suatu alat yang dapat membantu meringankan kegiatan menyiram tanaman. Alat tersebut berupa sistem yang dapat bekerja secara otomatis. Dengan menggunakan alat ini, maka diharapkan penyiraman tanaman dapat dilakukan pada waktu dan saat yang tepat.

\section{b. Melakukan Studi Pustaka}

Proses dalam melakukan penelitian ini, tahapan studi pustaka ini penulis lakukan untuk mendapatkan teori yang mendukung proses penelitian yang akan dilakukan, seperti buku, jurnal dan juga artikel - artikel yang ada di web.

\section{c. Persiapan Alat dan Bahan}

Pada tahapan ini merupakan tahapan dimana penulis mengumpulkan alat dan bahan yang akan digunakan seperti, arduino uno, rain sensor, module relay, model GSM serta box untuk menyusun alat - alat yang digunakan.

\section{d. Perancangan Arsitektur Sistem}

Sistem ini dirancang untuk penyiraman tanaman otomatis dengan bantuan aplikasi android yang dihubungkan dengan arduino uno, dimana untuk deteksi proses penyiraman tanaman ini, penulis menggunakan rain sensor yang nantinya akan menginformasikan tanaman sudah disiram atau belum. Dalam proses penyiraman tanaman, akan dikendalikan oleh arduino uno dengan bantuan module relay yang akan menghidupkan mesin air untuk menyiram air. Adapun gambaran dari sistem yang akan di rancang adalah sebagai berikut.

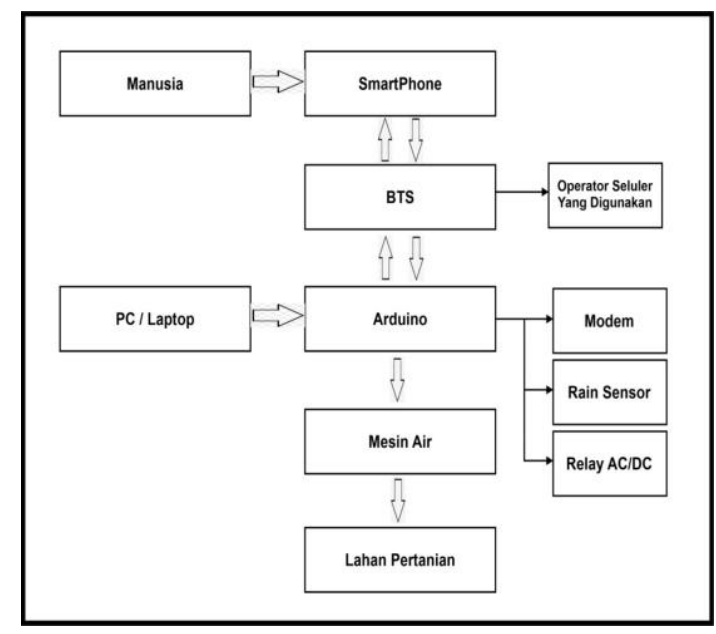

Gambar 3. Arsitektur Perancangan Sistem

Sedangkan untuk rangkaian secara jelasnya dapat dilihat seperti berikut ini. 
Jurnal Pseudocode, Volume VII Nomor 2, September 2020, ISSN 2355-5920, e-ISSN 2655-1845 www.ejournal.unib.ac.id/index.php/pseudocode

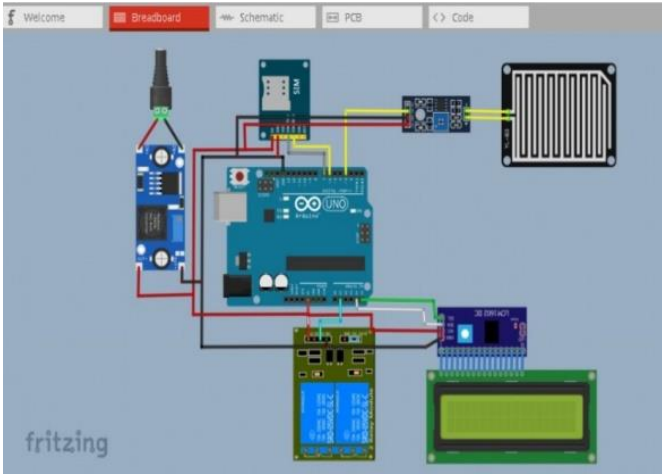

Gambar 4. Rangkaian Arsitektur Sistem

\section{e. Perakitan Sistem}

Tahapan ini merupakan tahapan diatas telah dilakukan, maka selanjutnya perakitan sistem akan dilakukan. Perakitan sistem ini bertujuan untuk menghubungkan semua perangkat atau komponen yang akan digunakan agar dapat saling terhubung anatara satu dengan yang lainnya dan berjalan sesuai dengan yang diinginkan.

\section{f. Pengujian Sistem}

Pengujian dilakukan dengan tujuan untuk mengetahui apakah data yang dihasilkan sesuai dengan apa yang diharapkan sehingga bisa dipertanggung jawabkan kebenarannya.

\section{HASIL DAN PEMBAHASAN}

Hasil dari penelitian yang telah dilakukan adalah sebuah alat ataupun sistem yang mampu di kontrol untuk melakukan tugas penyiraman tanaman otomatis menggunakan bantuan aplikasi android. Proses penyiraman tanaman ini akan dikirimkan melalui aplikasi android yang kemudian akan di proses oleh arduiono uno. Adapun hasil rangkaian alat yang sudah penulis rancang adalah sebagai berikut.

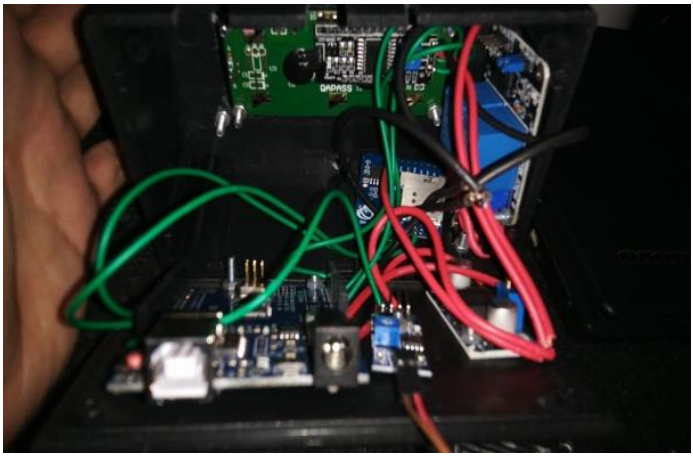

Gambar 5. Rangkaian Sistem

Setelah dilakukan perakitan terhadap sistem yang sudah di rencanakan, selanjutnya dilakukan pengujian. Adapun pengujian yang dilakukan adalah sebagai berikut.

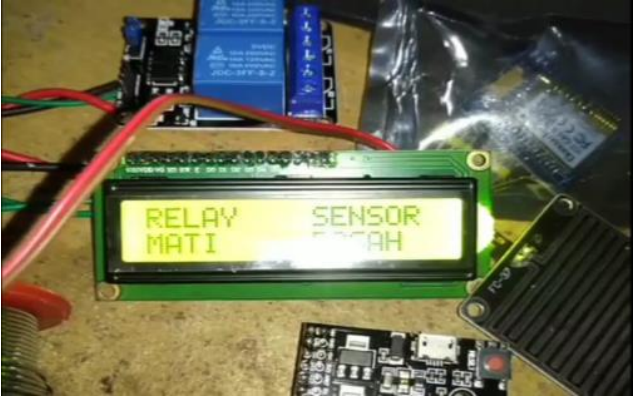

Gambar 6. Pengujian Alat Penyiram Tanaman

Dari proses pengujian tersebut, dapat dilihat bahwa ada informasi saat sensor sedang basah, maka relay yang digunakan untuk menghidupkan mesin air dimatikan. Selain melihat langsung pada alat penyiram tanaman, informasi dari status tanaman juga dapat dilihat pada aplikasi android yang digunakan. Adapun hasilnya dapat dilihat seperti berikut ini. 
Jurnal Pseudocode, Volume VII Nomor 2, September 2020, ISSN 2355-5920, e-ISSN 2655-1845 www.ejournal.unib.ac.id/index.php/pseudocode

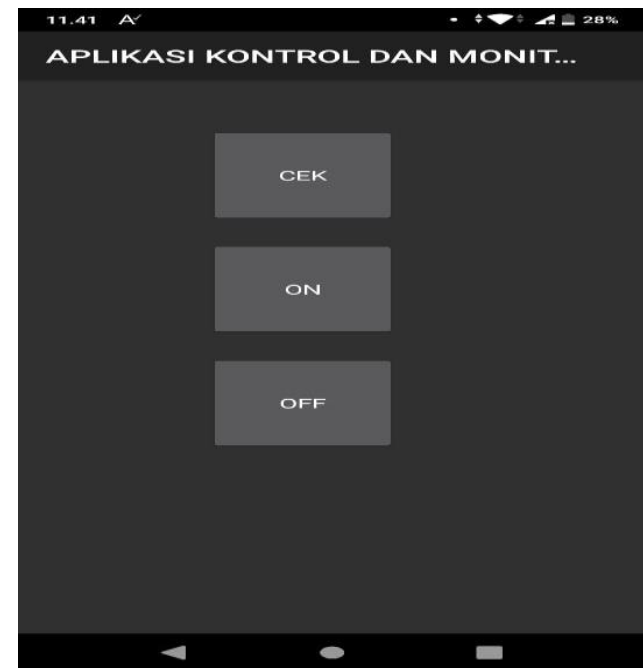

Gambar 7. Tampilan Aplikasi Android

Untuk melakukan pengecekan terhadap

kondisi tanah pada tanaman dapat dilakukan dengan menekan tombol cek, sehingga akan menampilkan pesan sebagai berikut.

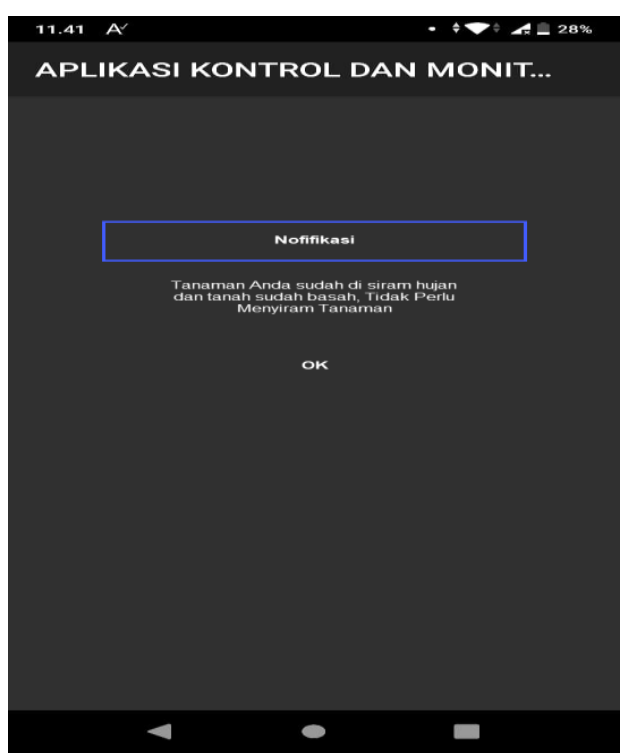

Gambar 8. Pesan Kelembaban Tanah Mengunakan Sensor hujan

Untuk memberikan gambaran hasil dari pengujian yang sudah dilakukan dari tiap - tiap percobaan, dapat dilihat pada tabel berikut ini.
Tabel 1. Pengujian Penyiraman Tanaman

\begin{tabular}{|c|c|c|}
\hline Percobaan & Koneksi & Waktu Respon \\
\hline Percobaan 1 & Terhubung & 30 Detik \\
\hline Percobaan 2 & Terhubung & 20 Detik \\
\hline Percobaan 3 & Terhubung & 27 Detik \\
\hline Percobaan 4 & Terhubung & 25 Detik \\
\hline Percobaan 5 & Terhubung & 30 Detik \\
\hline
\end{tabular}

Dari Tabel 1. Pengujian Penyiraman Tanaman ditas, sudah dilakukan beberapa pengujian untuk proses penyiraman tanaman dari aplikasi android yang dikirim ke arduino uno dengan hasil adanya waktu respon agar alat dapat melakukan tugas yang sudah di berikan oleh aplikasi android dengan rata - rata waktu respon 26,4 Detik.

\section{REFERENSI}

[1] E. Z. Kafiar, E. K. Allo, and D. j. Mamahit, "Rancang Bangun Penyiram Tanaman Berbasis Arduino Uno Menggunakan Sensor Kelembaban Y1-39 Dan Y1-69," J. Tek. Elektro dan Komput., vol. 7, no. 3, pp. 267-276, 2018.

[2] D. Prayama, A. Yolanda, and A. W. Pratama, "Rancang Bangun Alat Pengontrol Penyiram Tanaman Otomatis Menggunakan Sensor Kelembaban Tanah Di Area Pertanian," J. RESTI (Rekayasa Sist. dan Teknol. Informasi), vol. 2, no. 3, pp. 807-812, 2018.

[3] Y. F. Hidayat, A. H. Hendrawan, and Ritzkal, "Purwarupa Alat Penyiram Tanaman Otomatis menggunakan Sensor Kelembaban Tanah dengan Notifikasi Whatsapp," Pros. Semnastek, no. iv, pp. 1-2, 2019.

[4] S. Fina and I. Zendi, "Perancangan Score Board dan Timer Menggunakan Led RGB Berbasis Arduino dengan Kendali Smarth Phone Android," SINERGI, vol. 19, no. 1, pp. 4-6, 2016.

[5] Nasrullah, E., Trisanto, A., \& Utami, L. (2011). Rancang bangun sistem penyiraman tanaman secara otomatis menggunakan sensor suhu $\operatorname{lm} 35$ berbasis mikrokontroler atmega8535. Electrician, 5(3), 182-192.

[6] Junaidi. 2018. Project Sistem Kendali Elektronik Berbasis Arduino. Aura : Bandar Lampung

[7] Supegina, F., \& Iklima, Z. (2015). Perancangan Score Board Dan Timer Menggunakan Led Rgb Berbasis Arduino Dengan Kendali Smart Phone Android. Sinergi, 19(1), 13-18.

[8] Septryanti, A., \& Fitriyanti, F. (2017). Rancang Bangun Aplikasi Kunci Pintu Otomatis Berbasis Mikrokontroler Arduino Menggunakan Smartphone Android. Computer Engineering, Science and System Journal, 2(2), 59-63.

[9] Jaelani, I., Sompie, S. R., \& Mamahit, D. J. (2015). Rancang Bangun Rumah Pintar Otomatis Berbasis Sensor Suhu, Sensor Cahaya, Dan Sensor Hujan. Jurnal Teknik Elektro dan Komputer, 5(1), 1-10.

[10] Kafiar, E. Z., Allo, E. K., \& Mamahit, D. J. (2018). Rancang Bangun Penyiram Tanaman Berbasis Arduino Uno Menggunakan Sensor Kelembaban Y1-39 Dan Y169. Jurnal Teknik Elektro dan Komputer, 7(3), 267-276 